\title{
SOBRE A FRAGILIDADE DA EXISTÊNCIA HUMANA NAS CONFISSÕES, XI
}

\author{
On Human Fragility in the Confessions, XI
}

\author{
Lúcio Souza Lobo ${ }^{1}$ \\ João Pedro da Luz Neto ${ }^{2}$
}

\begin{abstract}
RESUMO: Questionando a respeito dos motivos que levaram Agostinho a tratar do tempo, tema frequentemente associado à metafísica e cosmologia, em sua obra Confissões, cujo caráter é autobiográfico, aventamos a hipótese de que o tema pertença ao projeto unitário da obra, cujas chaves de leitura seriam 1) a finalidade da vida humana e 2) a distinção entre Deus e as criaturas. Ao analisar a argumentação agostiniana, percebe-se que é possível inserir o debate em questão no âmbito geral da narrativa desta obra em específico. Percebe-se, ainda, que a partir desta ótica a abordagem psicológica não está necessariamente ligada à uma compreensão do tempo sob um aspecto meramente subjetivista, uma vez que a preocupação central da discussão não é com o aspecto metafísico/cosmológico e sim com a análise interior.
\end{abstract}

PALAVRAS-CHAVE: Tempo; Confissões XI; Agostinho de Hipona; Existência; Distentio animi.

\begin{abstract}
Questioning the reasons that led Augustine to reflect about time, a theme often associated with metaphysics and cosmology, in his work Confessions, which main character is autobiographical, we hypothesize that the theme belongs to the unitary project of the work, whose keys of reading would be 1) the purpose of human life and 2) the distinction between God and creatures. When analyzing the Augustinian argument, it is noticed that it is possible to insert the debate in question in the general scope of the narrative of this specific work. It is also noticed that, from this perspective, the psychological approach is not necessarily linked to an understanding of time from a purely subjectivist aspect, since the central concern of the discussion is not with the metaphysical / cosmological aspect, but with the analysis interior.
\end{abstract}

KEYWORDS: Time, Confessions XI, Augustine of Hippo, Existence, Distentio animi.

O livro XI de Confissões é célebre por sua reflexão acerca do tempo. Todavia, esta obra carece de alguns elementos que poderiam ser considerados básicos para a estrutura

\footnotetext{
${ }^{1}$ Doutor em filosofia pela Universidade Federal do Rio Grande do Sul (UFRGS) e professor do Departamento de Filosofia da Universidade Federal do Paraná (UFPR). E-mail: luciosouzalobo@gmail.com

2 Mestre e doutorando em filosofia pela Universidade Federal do Paraná (UFPR). E-mail: jpluzneto@gmail.com
} 
de uma reflexão metafísica ou cosmológica sobre o tema, como, por exemplo, uma definição de tempo - tal qual será proposta em outras obras do Hiponense (de Civitas Dei, de Genesis ad Litteram). Mas, mesmo que seja possível esclarecer o conceito de tempo em Confissões XI, através de um trabalho exegético minucioso sobre este texto, em conjunto com os tratados supracitados, em que o tempo é abordado de modo metafísico e cosmológico, há que se perguntar qual é a necessidade de uma reflexão a respeito da temporalidade dentro de um livro que pretende ser autobiográfico.

O trabalho que se origina desta pergunta, portanto, não se voltará especificamente à noção de tempo e eternidade enquanto conceitos filosóficos - enquanto conceitos que devem ser bem explicados e definidos à luz da visão agostiniana, mas enquanto prática reflexiva que se insere num contexto mais amplo do projeto unitário de Confissões, qual seja, 1) a finalidade da vida humana e 2) o reconhecimento da distinção entre Deus e a criatura.

Ao estabelecer esta proposta de leitura, nos unimos a outros comentadores, como Christian Tornau ${ }^{3}$, para quem o propósito de Confissões XI é ético, e não cosmológico, ou ainda Philipe Hoffmann, para quem

A análise do tempo, por mais enigmática e aporética que seja, é um exercício espiritual, uma exercitatio animi destinada a permitir a consciência dessa lacuna entre a eternidade divina e o tempo humano, e uma expressão da miséria da vida da alma dispersa ${ }^{4}$.

Nosso objetivo é principalmente trabalhar um aspecto incluso dentro do tratamento de tempo e eternidade em Agostinho, qual seja, o aspecto da fragilidade (fragmentariedade) da vida do ser humano: que tipo de vida é possível a um ser que vive no tempo. Como se desenrola esta vida e como o quinhão de realidade que se tem a cada instante influi na caracterização da pobreza ontológica desse ser perante um ser que tem a vida eterna, ou seja, que tem a vida em plenitude.

\footnotetext{
3 TORNAU, Christian, "Saint Augustine", The Stanford Encyclopedia of Philosophy (Summer 2020 Edition), Edward N. Zalta (ed.). Disponível em: https://plato.stanford.edu/archives/sum2020/entries/augustine/.

${ }^{4}$ Tradução nossa. No original: L'analyse du temps, si énigmatique et aporétique soit-elle, est un exercice spirituel, une exercitatio animi destinée à permettre une prise de conscience de cet écart entre l'éternité divine et le temps humain, et une expression de la misère de l'âme dispersée. HOFFMANN, Philippe. Temps et éternité dans le livre XI des Confessions: Augustin, Plotin, Porphyre et Saint Paul. Revue D'Etudes Augustiniennes et Patristiques, [S.L.], v. 63, n. 1, p. 31-79, jan. 2017. Brepols Publishers NV. http://dx.doi.org/10.1484/j.rea.4.2017072.
} 


\section{Tempo e eternidade}

É em 14, 17 de Confissões XI que Agostinho se interroga diretamente sobre o que é o tempo e evoca o tratado plotiniano sobre o assunto (Enéada III, 7), ao afirmar que, quando não é interrogado, sabe o que o tempo é, mas não o sabe o que ele é quando lhe perguntam. É também a partir do mesmo tratado que Agostinho tomará uma concepção fundamental, a respeito da diferença entre o tempo e a eternidade.

"Dizendo que eternidade e tempo são diferentes entre si, uma concernindo à natureza perpétua e o tempo, ao devir e a este universo, pensamos ter em nossas próprias almas, espontaneamente e como por intuições mais densas do pensamento, uma experiência manifesta acerca deles, referindo-nos sempre a eles e evocando-os a respeito de tudo. No entanto, quando tentamos nos concentrar neles e como que deles nos aproximar, ficamos perplexos com nossos pensamentos..." 5

Se o Hiponense se diz, tal qual Plotino, incapaz de expressar em palavras o que o tempo é, ele sabe, no entanto, uma de suas características essenciais: ele se divide em passado, presente e futuro. O presente é, de alguma maneira, garantido: é o que é nesse instante. Mas no passado e no futuro o é se transforma em "foi" e "será", de modo que não possuem o mesmo status ontológico do presente. Se por um lado passado e futuro não possuem essa instanciação ontológica como o tempo presente, não podem ser negados, pois a existência individual do presente o tornaria uma eternidade: "o presente, se fosse sempre presente e não se tornasse passado, não seria presente, e sim eternidade"6.

Deus, como o filósofo argumentou nos capítulos anteriores, não está sujeito ao tempo: para isso, pôs-se a refletir sobre a pergunta desafiadora dos céticos ${ }^{7}$ sobre o "Que fazia Deus, antes de criar o céu e a terra?", e obtém como resposta que a própria pergunta parte de um pressuposto equivocado. Afinal, ao perguntar o que fazia Deus antes de criar o mundo, supõe-se que Deus esteja imerso no tempo, o que, para o Hiponense, não procede. Ao longo de toda a análise das Confissões, Agostinho se mostra resistente à ideia de

\footnotetext{
${ }^{5}$ PLOTINO. Enéadas III.7 (45), 1. In: BACARAT JÚNIOR, José Carlos. Plotino, Enéadas I, II e III; Porfírio, Vida de Plotino: introdução, tradução e notas. 2006. 700 f. Tese (Doutorado) - Curso de Linguística, Universidade Estadual de Campinas, Campinas, 2006.

6 AgOSTINHO. Confissões. São Paulo: Cia das Letras/Penguin, 2017. Edição Kindle. Para facilitar o trabalho de consulta, citaremos conforme o modo de citação mais tradicional: Conf. XI, XIV, 17.

${ }^{7}$ MATTHEWS, Gareth. Santo Agostinho: A vida e as ideias de um filósofo adiante de seu tempo. Rio de Janeiro: Jorge Zahar, 2007, p. 127.

${ }^{8}$ Conf. XI, X, 12.
} 
conceber Deus na mesma categoria das substâncias ${ }^{9}$. No caso do tempo, percebe-se que tudo o que é, resulta de Deus: "Com efeito, se fizesses algo, o que farias a não ser uma criatura?"10, e se algo foi, em algum momento teve também uma existência dada por Deus. Por conseguinte, o próprio passado, enquanto algo que já foi existente, dependeu de Deus. "De fato, tu fizeste aquele tempo, e os tempos não poderiam passar, antes que fizesses os tempos"11. A conclusão, com efeito, é a de que o próprio Deus criou o tempo, pelo que perguntar a respeito dele antes do tempo não tem qualquer sentido. "Mas, se não havia tempo antes do céu e da terra, por que perguntam o que fazias então? Não havia "então", onde não havia tempo"12.

Pois bem: para Agostinho tratar do tempo, ele usa a contraposição entre tempo e eternidade, argumentando que Deus é um ser perfeito e simples e que Ele é a própria eternidade. Não só vive na eternidade, mas Ele é a própria eternidade. Um século mais tarde, Boécio definirá a eternidade como a "perfeita possessão, total e em simultâneo ${ }^{13}$, da vida infinita" ${ }^{\prime 4}$. Mas o que seria essa vida sem limites? Só poderíamos situá-la mediante a comparação com o nosso tipo de vida. Enfatiza-se, então, a radicalidade da distância entre Deus e a humanidade, à medida em que para esta há a completa sujeição no tempo: “Teus anos não vão nem vêm: estes nossos vão e vêm, para que venham todos"15.

Mas como é, então, a percepção do tempo em nosso tipo de vida? É bem caracterizado quando Agostinho expõe o tempo como algo que se realiza só no instante presente. $\mathrm{O}$ Hiponense considera o tempo sob seu aspecto de extensão o que, no entendimento de Gilson, "parece uma simplificação excessiva da solução de Aristóteles"16. Ao longo do capítulo XV, Agostinho se interroga sobre o que seria a divisão do tempo entre passado, presente e futuro e, como toda extensão, uma vez que há uma propriedade inerente à

\footnotetext{
${ }^{9}$ Cf. por exemplo, Conf. VII, X, 16 ou Conf. IV, XVI, 29.

${ }^{10}$ Conf. XI, XII, 14.

${ }^{11}$ Conf. XI, XIII, 15.

${ }^{12}$ Conf. XI, XIII, 15.

${ }^{13}$ O termo "simultâneo" pode causar ambiguidade na leitura, pois pode ser tomado em mais de um sentido. No caso específico de Boécio, parece indicar o sentido de uma simultaneidade como não-sucessividade. Nas palavras de Almeida Fleck: "O conceito de simultaneidade (...) se pode aplicar em dois sentidos diversos: ou ao eterno em si mesmo, ou ao eterno com respeito ao temporal: pode-se pretender que "na eternidade tudo é simultâneo" ou que "o eterno é simultâneo ao temporal". Chamaremos à primeira acepção "simultaneidade interna" e à segunda "simultaneidade externa" (...) A simultaneidade interna atribuída à eternidade é simplesmente sua não-sucessividade." (ALMEIDA FLECK, Fernando Pio. Eternidade, Negação e Conhecimento. In: Analytica, vol. 7, nº1. 2003, pp. 83-96).

${ }_{14}$ BOÉCIO. Consolação da Filosofia. Lisboa: Fundação Calouste Gulbenkian, 2016. Livro V, prosa 6.

${ }^{15}$ Conf. XI, XIII, 16.

${ }^{16}$ GILSON, Etienne. Introdução ao estudo de Santo Agostinho. São Paulo: Discurso Editorial/Paulus, 2006, p. 366.
} 
extensão ser divisível ad infinitum, conclui que o tempo presente não pode ser algum tipo de extensão:

Se for possível conceber um elemento do tempo cujo momento não possa ser dividido em partes minutíssimas, só este poderia ser chamado presente; todavia, ele passaria tão imediatamente do futuro para o passado, que não se estenderia por duração alguma ${ }^{17}$.

Ao se interrogar, então, sobre como medimos o tempo, Agostinho propõe o conceito de distensão da alma (distensio animi) ${ }^{18}$, que permite a concatenação entre o permanente e o transitório. Ao coincidir três dimensões do tempo num mesmo instante real, através da concatenação entre passado-memória, futuro-expectativa ${ }^{19}$ e presente-visão $^{20}$, Agostinho insere a leitura do tempo no âmbito psicológico, não necessariamente por ser um subjetivista no seu sentido mais forte, mas para, pelo menos, mostrar que a percepção que nós temos de tempo é dependente de funções do nosso próprio intelecto, ou seja, do que se passa em nós. Agostinho advoga: "Em ti, minha mente, meço os tempos"21.

Tornando possível a coexistência entre passado, presente e futuro, através de um tipo de distensão da alma, Agostinho torna possível a percepção da duração, e agora há como medirmos o tempo. O exemplo da canção ${ }^{22}$ é bastante ilustrativo desta passagem: antes de ser cantada, ela é totalmente futuro. Ao ser cantada, transforma-se em passado. Mas é o presente é o lugar da atenção e de transformação entre o futuro e o passado. O que vale para a canção, afirma o Hiponense, vale para a sílaba, para as ações humanas, para a vida inteira e para a história.

Resta, então, que para Deus as palavras "antes" e "depois" carecem de significação. “Tu és o criador eterno de todos os tempos e nenhum tempo é coeterno contigo, nem criatura alguma, mesmo se houver alguma anterior aos tempos" ${ }^{23}$. Qual é o tipo de conhecimento alçado por Ele? Alguma "maneira muito mais admirável e secreta"24. Criador das mentes e verdadeira eternidade, em Deus não há sucessão temporal. Nas palavras de Matthews: “O ato de criação por Deus é um ato eterno no sentido de ser um

\footnotetext{
${ }^{17}$ Conf. XI, XV, 20.

${ }^{18}$ Conf. XI, XXIII, 30 e XI, XXVI, 33.

${ }^{19}$ Conf. XI, XX, 26. Na tradução da ed. Paulus, o termo latino "expectatio" foi traduzido como "espera".

${ }^{20}$ Conf. XI, XX, 26.

${ }^{21}$ Conf. XI, XXVII, 36.

${ }^{22}$ Conf. XI, XXVIII, 38.

${ }^{23}$ Conf. XI, XXX, 40.

${ }^{24}$ Conf. XI, XXXI, 41.
} 
ato não-temporal. E os objetos que ele criou para iniciar o tempo devem ter sido cridos em um estado de movimento, ou mudança" 25 .

\section{A contingência do instante presente}

Essa é a ideia básica de Agostinho. Ele mostra o quê? Mostra que o nosso presente, ou seja, a nossa vida real se dá nesse instante, neste átimo, ou neste ponto, como se trataria de uma extensão linear. Vivemos agora.

Nos interrogaremos, adiante, se este modo de tratamento do tempo representa, ou não, uma recusa do tempo exterior. De qualquer modo, o que nos interessa, nesse momento, é um aspecto ressaltado a partir do tempo - justamente o do modo de vida do ser humano. Temos, todos nós, uma experiência manifesta acerca do devir. De acordo com a percepção de realidade, da visão de mundo, e até a própria vida, pode-se pensar o tempo e a vida nele inserida como uma realidade natural e imediata. Disto, poder-se-ia supor que o tempo é tão natural que nem sequer se avente a hipótese de um outro tipo de realidade ou de vida. Ao longo da história da filosofia, tentou-se pensar se não haveria algum tipo de contraposição a este modo temporal da vida humana, e postulou-se, em oposição ou alternativamente à temporalidade, a eternidade de certas verdades, como as verdades matemáticas ou certos princípios metafísicos.

Mas o que leva Agostinho a pensar sobre esse assunto dentro de uma obra autobiográfica? Qual é a função desta discussão dentro da obra de Agostinho? O que ele quer revelar dentro desse tratamento?

A nossa hipótese de leitura, que até o momento nos parece a mais adequada, é que o conjunto de louvores que Agostinho faz a Deus, em Confissões, aponta para duas coisas: 1) a finalidade da vida humana e 2) o reconhecimento da distinção entre Deus e a criatura.

O reconhecimento da distinção entre Deus e o ser humano aponta para um modo de ser da criatura que é frágil e que, de alguma maneira sofre, a cada instante, a corrupção. Não apenas nos tornamos, a cada instante, um passado, mas principalmente, enfrentaremos, em algum momento, a morte. Ao longo da vida, a nossa existência deixa de ser tudo o que era, perdendo-se no passado, permanecendo apenas na memória, e aponta para um futuro que não se concretizou e pode nem se concretizar, uma vez que o término deste ser, ou seja, a morte, a desagregação, a corrupção pode se dar em qualquer

\footnotetext{
${ }^{25}$ MATTHEWS, Gareth. Santo Agostinho: A vida e as ideias de um filósofo adiante de seu tempo. Rio de Janeiro: Jorge Zahar, 2007, p. 123.
} 
instante. A morte é uma condição humana radical, presente já nas primeiras frases de Confissões: "Quer te louvar o homem, fragmento qualquer de tua criação, e anda em círculos carregando sua mortalidade" 26 . Nas palavras de Jorge Coutinho,

Para Agostinho é isso existir: estar diante de Deus, nessa tensão dramática da plenitude existencial, sem desespero de tragédia, mas na certeza antecipada de que buscar a Deus é buscar a vida eterna. E nessa vivência do eu humano, frágil e finito, diante do Tu absoluto e infinito de Deus que ele vai desvelando o mistério de si e o mistério de Deus ${ }^{27}$.

O tema da fragilidade da vida é muito caro para Agostinho. Encontramo-lo não apenas em diversas passagens de Confissões, mas também em outras obras: "Como pois retê-las a fim de que permaneçam, essas realidades para as quais iniciar a existir é idêntico a caminhar para o nada?"28; "Pois, do mesmo modo como o corpo, privado de alimento, fica exposto a doenças e reações malignas decorrentes de sua inanição, assim o espírito ignorante está impregnado de doenças provenientes de suas carências"29; ou ainda: "Mesmo aquilo a que os homens chamam, com propriedade, corrupção do corpo ou seja, a putrefacção, se ainda tem alguma coisa para profundamente destruir, só aumenta pela diminuição do que é bom"30.

Mas o que significa essa fragilidade? O pó para onde caminhamos ${ }^{31}$ há de ser o final? Não para Agostinho: "que eu me conheça a mim mesmo; que eu te conheça." 32 . O socratismo agostiniano, ou seja, o voltar-se para si, é o ponto de partida para um ulterior: "nosso coração é inquieto, até repousar em ti" ${ }^{33}$. Mas de que modo o coração humano aponta, como fim último, para Deus? Confissões, como um todo, são um prospecto deste itinerário ${ }^{34}$. Justamente por isso que, limitando-nos ao escopo do artigo, referimo-nos a esse caminho de modo bastante sucinto, tendo em vista indicar o modo pelo qual a discussão sobre o tempo pode ser lida à luz deste itinerário até o repouso em Deus.

O ser humano, por sua natureza intelectiva, aponta para sua existência em uma continuidade de vida que se dá mesmo após a morte. Agostinho reconhece que no ser humano há algo de imaterial (intelecto, vontade) e que isso não é corruptível. Afinal, não

\footnotetext{
${ }^{26}$ Conf. I, I, 1.

${ }^{27}$ COUTINHO, Jorge. Essencialidade e Existencialidade em Santo Agostinho. Lisboa: Revista Didaskalia, v.19, nº1 (1989), p. 103.

${ }^{28}$ AGOSTINHO. O livre-arbitrio. São Paulo: Paulus, 1995, III, 7, 21.

${ }^{29}$ AGOSTINHO. Solilóquios; A vida feliz. São Paulo: Paulus, 1998. De beata vita, II, 8.

${ }^{30}$ AgOSTINHO. A natureza do bem. Porto (Portugal): Fundação Eng. António de Almeida, 1992. no 20.

${ }^{31}$ A BÍBLIA DE JERUSALÉM. São Paulo: Paulus, 2002. Eclesiastes, 12, 7.

${ }^{32}$ AGOSTINHO. Solilóquios; A vida feliz. São Paulo: Paulus, 1998. Sol., II, 1.

${ }^{33}$ Conf. I, I, 1.

${ }^{34}$ Destacamos ainda que Gilson (Introdução ao estudo de Santo Agostinho) vê, no conjunto da obra do Hiponense, um itinerário completo de saída do exterior rumo ao interior.
} 
seria possível contemplar as verdades eternas e imateriais se não houvesse, no próprio ser humano, algo com semelhantes características.

Se tudo o que é próprio do sujeito permanece para sempre, é de necessidade que também o próprio sujeito permaneça. Toda ciência está na alma como sujeito. E se a ciência permanece sempre, necessariamente permanece a alma para sempre. Ora, a ciência é verdade, e a verdade, como a razão o demonstrou no início deste livro, permanece para sempre. Por isso, a alma permanece para sempre e não se diz que a alma tenha morrido ${ }^{35}$.

Mais do que isso, pode-se acrescentar que, como na natureza não se produz nada em vão, um ser que possua a capacidade intelectual, por natureza, tende ao conhecimento infinito, que não poderia de forma alguma ser alcançado numa vida limitada. Ora, se é assim, seria incoerente, ou mesmo contraditório, pensar que a natureza produza um ser com potência para o conhecimento ilimitado e esse conhecimento, por natureza, não possa ser alcançado. A vida eterna, a bem-aventurança prometida nas Sagradas Escrituras dizem respeito também a esse aspecto do ser humano, que é a contemplação, senão total, ao menos a possibilidade de crescimento de conhecimento de forma indefinida, em uma vida que também não tenha fim.

Outrossim, a possibilidade de reconhecer essa fragilidade da vida humana do presente atual permite a Agostinho de alguma maneira mostrar que este estado ontológico frágil, passageiro, aponta para algo superior. A tentativa, o esforço de Agostinho é mostrar no nosso entender o seguinte: há em Deus uma plenitude de Ser, que chamamos de eternidade, e seremos partícipes de alguma forma dessa eternidade. Nunca seremos eternos no rigor dos termos, mas teremos, sim, a possibilidade de uma vida sem fim em um outro nível de existência.

Para o ensaísta contemporâneo Fabrice Hadjadj, a bem-aventurança tem uma característica de excesso; o transbordamento provocado pela eternidade não se reduz à um paraíso impessoal, mas a uma abundância da pessoalidade, “(...) de modo que no céu eu seria mais ainda eu mesmo" 36 . De fato, as diversas possibilidades de enriquecimento do ser humano quando da bem-aventurança é muito mais ampla do que o coroamento da potência cognitiva. Diz respeito também àquilo que no ser humano é paz, é amor, etc. Se nos restringimos aqui à potência intelectiva é apenas como exemplo de como isso deve

\footnotetext{
${ }^{35}$ AGOSTINHO. Solilóquios; A vida feliz. São Paulo: Paulus, 1998. Sol., II, 13.

${ }^{36}$ HADJADJ, Fabrice. Paraíso à porta: Ensaio sobre uma alegria que desconcerta. São Paulo: É realizações, 2015, p. 28.
} 
funcionar; além disso, é por meio dela que Agostinho lida com o problema da alma. Em suma: esse outro nível possibilita uma vida ilimitada, em oposição ao nível fragmentário deste mundo. Nesta outra vida postulada por Agostinho, a bem-aventurança permitirá, com respeito à potência intelectiva, um conhecimento cognitivo que não terá fim.

\section{Uma visão subjetivista?}

Inserida a discussão do tempo no âmbito maior de Confissões, ao estabelecer que na discussão agostiniana a finitude da vida humana, através da contemplação divina, encontra-se no âmbito da eternidade, resta-nos apenas compreender se a noção de distensio animi, utilizada pelo Hiponense para enfatizar o caráter interior do tempo, o reduz ao âmbito psicológico ou não.

Embora Confissões XI seja bastante difundida, sabemos que não é a única obra de Agostinho sobre o assunto. Em Cidade de Deus XI e XII o tempo também recebe outro tipo de tratamento e, ao invés de entendê-lo como algo mental, o filósofo argumenta que o tempo é a medida do movimento e que há um tempo celeste ordenado ${ }^{37}$. Conclusões que, aparentemente, são bastante diferentes às de Confissões XI. Matthews argumentará que não se trata de uma mudança de perspectiva, mas descrições diferentes do tempo. Valendo-se de uma distinção entre série-A e série-B, proposta pelo filósofo britânico McTaggart, Matthews afirma que Confissões e Cidade de Deus se completam como duas descrições diferentes sobre o tempo ${ }^{38}$.

Como consequência de nossa leitura, podemos apontar a concordância com a solução da aparente discrepância entre as posições agostinianas de Confissões XI e Cidade de Deus XI e XII, já defendida Matthews, ao argumentar em favor de uma distinção de propósito ou ponto de vista, e não uma incoerência doutrinal (ou mudança de pensamento). Afinal, se Confissões XI não está apresentada enquanto uma abordagem completa acerca do problema do tempo, mas apenas como uma abordagem psicológica que ressalta o caráter interior da relação com Deus, então não há necessidade de se afirmar um subjetivismo agostiniano.

\footnotetext{
${ }^{37}$ MATTHEWS, Gareth. Santo Agostinho: A vida e as ideias de um filósofo adiante de seu tempo. Rio de Janeiro: Jorge Zahar, 2007, p. 130.

${ }^{38}$ MATTHEWS, Gareth. Santo Agostinho: A vida e as ideias de um filósofo adiante de seu tempo. Rio de Janeiro: Jorge Zahar, 2007, p. 133.
} 
Em consequência, se quisermos chamar Agostinho de subjetivista, para ressaltar o seu tratamento psicológico de Confissões, seria bom que se acrescentasse, ao lado deste termo, o termo "mitigado". Afinal de contas, não se trata de uma perspectiva como a de Kant, em que o tempo não existe em $\mathrm{si}^{39}$. Agostinho apenas enfatiza a fragilidade do modo de existência do ser humano mediante aspectos incontestáveis da nossa experiência. Para ele, essa prova psicológica não quer dizer que o tempo se reduza a algo de natureza mental.

À guisa de conclusão: por que se internaliza a análise do tempo em Confisssões? Porque Confissões tem como foco a análise interna: trata-se de uma ênfase no mundo interior de Agostinho. Ao menos nesta obra, o seu subjetivismo é um ponto fundamental, conquanto o seu ponto de partida. Daí, não decorre que o tempo seja, per se, uma categoria mental. Mas qual é a vantagem que Agostinho vê ao abordar de um modo psicológico o problema do tempo? Defendemos que a sua abordagem enfatiza a distância entre Deus e os homens, ao estabelecer para um a eternidade e para outro a contingência, e que essa contingência, como sinal da fragilidade, também indica uma radical dependência para com Deus. É como índice do modo de existência frágil da vida humana que Agostinho aborda o problema do tempo em sua obra.

\section{Referências}

AGOSTINHO. A natureza do bem. Porto: Fundação Eng. António de Almeida, 1992.

AGOSTINHO. Confissões. São Paulo: Cia das Letras/Penguin, 2017.

AGOSTINHO. Confissões. São Paulo: Paulus, 1997.

AGOSTINHO. Las Confesiones. Madrid: BAC, 1979.

AGOSTINHO. O livre-arbitrio. São Paulo: Paulus, 1995.

AGOSTINHO. Solilóquios; A vida feliz. São Paulo: Paulus, 1998.

ALMEIDA FLECK, Fernando Pio. Eternidade, Negação e Conhecimento. In: Analytica, vol. 7, nº1. 2003, p. 83-96.

BACARAT JÚNIOR, José Carlos. Plotino, Enéadas I, II e III; Porfírio, Vida de Plotino: introdução, tradução e notas. 2006. 700 f. Tese (Doutorado) - Curso de Linguística, Universidade Estadual de Campinas, Campinas, 2006.

${ }^{39}$ KANT, I. Crítica da Razão Pura. Lisboa: Fundação Calouste Gulbenkian, 2001. KrV A32/B49. 
A BÍBLIA DE JERUSALÉM. São Paulo: Paulus, 2002.

BOÉCIO. Consolação da Filosofia. Lisboa: Fundação Calouste Gulbenkian, 2016.

COUTINHO, Jorge. Essencialidade e Existencialidade em Santo Agostinho. Lisboa: Revista Didaskalia, v.19, $\mathrm{n}^{\circ} 1$ (1989)

GILSON, Etienne. Introdução ao estudo de Santo Agostinho. São Paulo: Discurso Editorial/Paulus, 2006

HADJADJ, Fabrice. Paraíso à porta: Ensaio sobre uma alegria que desconcerta. São Paulo: É Realizações, 2015.

HOFFMANN, Philippe. Temps et éternité dans le livre XI des Confessions: Augustin, Plotin, Porphyre et Saint Paul. Revue D'Etudes Augustiniennes Et Patristiques, [S.L.], v. 63, n. 1, p. 31-79, jan. 2017. Brepols Publishers NV.

KANT, I. Crítica da Razão Pura. Lisboa: Fundação Calouste Gulbenkian, 2001.

MATTHEWS, Gareth. Santo Agostinho: A vida e as ideias de um filósofo adiante de seu tempo. Rio de Janeiro: Jorge Zahar, 2007, p. 123.

TORNAU, Christian, "Saint Augustine", The Stanford Encyclopedia of Philosophy (Summer 2020 Edition), Edward N. Zalta (ed.). Disponível em: https://plato.stanford.edu/archives/sum2020/entries/augustine/. 